\title{
Environmental Stewardship and Strategy for Business Sustainability: Evidence from Small and Medium Packaged Water Enterprises in Nigeria
}

\author{
Idowu Emmanuel OLUBODUN ${ }^{1}$ \\ Yinusa Toyese AGBAJE
}

DOI: $10.24818 / \mathrm{mer} / 2021.06-02$

\begin{abstract}
Climate change phenomenon and non-biodegradable nature of some industrial outputs are creating an increasing awareness and need to balance economic activities with social and environmental demands of the society. Also the rising concerns of government, consumers and the society at large regarding whether organisations see the necessity for the balance is gaining more momentum. In this regards, this paper seeks to examine the relationship between environmental stewardship and business sustainability. Research survey is used in which environmental stewardship proxy as community engagement activities, recycling activities, and waste reduction and management activities were investigated on business sustainability which is viewed along three dimensional (economic, social and environmental) balances in the questionnaire. The data were analysed using descriptive statistics while multiple regression was employed to determine the effect of environmental stewardship on business sustainability. The two objectives were achieved as stated. The results show that there is positive significant effect of environmental stewardship on business sustainability at p-value $<0.05$. Also, waste reduction and management has the highest mean value of 3.021 compared to others. The study concludes that recycling and waste reduction and management actions will enhance business sustainability. Future studies are suggested.
\end{abstract}

KEYWORD: business sustainability, community engagement, environmental stewardship, recycling, waste reduction and management.

JEL CLASSIFICATION: $M 10, Q 01, Q 56$

\section{INTRODUCTION}

Increasing pressure is mounting on the environment due largely to habitat destruction, disruption, pollution, climate change resulting from human activities and natural resource extraction (Sustainable Development Goals Report, 2019). It is already envisaged in extant literature that the society will take its portion of this circumstances (Hardin, 1968; Mercer, 2004; Williams \& Ponsford, 2008; Wong, 2004; World Tourism Organization, 2008b). This further confirms that the environment is a complex interactive system comprising the atmosphere, land surface and bodies of water including living things (Federal Ministry of Environment,2016). One among other factors that could account for this experience is change in the lifestyle of people which is skewed towards life on the go particularly because of transition from analog to digital way of life (Amusa, 2018). The phenomenon permeates the fabric of the entire society but more with younger age. However, every stratum of the society

\footnotetext{
${ }^{1}$ Obafemi Awolowo University, Ile-Ife, Osun State, Nigeria, iolubodun@oauife.edu.ng, idowueolubodun@gmail.com, Corresponding author

${ }^{2}$ Obafemi Awolowo University, Ile-Ife, Osun State, Nigeria, toyeseagbaje@gmail.com
} 
should recognise the aftermath of this challenge and its contribution to or share from these environmental issues.

Generally, the motive of business owners is more towards profit making and increasing quest in level of business survival as one way to sustain themselves in operations. However, the pursuance of these objectives give virtually little or no consideration to environmental concerns (Menon \& Menon, 1997;

Charter \& Polonsky, 1999). The environmental impacts of business operations from procurement of resources to end-of-life-use of products are already manifesting in increased greenhouse gas (GHG) emissions and every form of business is culpable. The focus needs to change for businesses to stay relevant in the long run because there is need to become more responsible to the environment by ensuring that firms plan the natural environment into their business operations both for the short and long terms. This tends to provide the basis for competitiveness and help organisations withstand pressure that could likely come from regulations and environmentalists in the nearest future.

Climate change impacts and non-biodegradable nature of plastics water bottles and sachet nylon waste are sources of concerns to governments, consumers and the society at large. Products packaging constitute waste to the environment as often observed and noted that waste plastic bottles and sachet nylon are in our streets, commercial motor-parks, market places, event centres, landfills, dumpsites, drainages and canals. Further, packaged water industry is increasingly under pressure more than ever due to need to reduce, recycle, and reuse its waste in a bid to minimise plastics water bottles and sachet nylon impacts on the environment (Vanguard Newspapers: Feb.,24, 2020). The environmental issues among others are littering, landfills, municipal solid waste (MSW), increased heap of waste in dump sites and marine life litter disturbance. In this regards, most organisations engage in unethical practices such as plastics waste burning, indiscriminate dumping, street littering after end of life use of the content because of poor or weak regulatory framework and lack of shared responsibility among stakeholders. Poor recycling and reuse practices of waste plastics bottle and lack of repossession and reprocessing capacity of sachet nylon in particular is gradually threatening the sustainability of packaged water business globally and Africa in general (Jambeck, Hardesty, Brooks, Friend, Teleki, Fabres, Beaudoin, Bamba, Francis, Ribbink, Baleta, Bouwman, Knox \& Wilcox, 2018). Business leaders and owners' engagements in handling the environment should go beyond concerns for waste and litter but product sustainability initiatives which tends to lead to business continuity. One way to address this is for business enterprises to adopt and embrace environmental stewardship practise. Comfortably, production, marketing and consumption of this product contributes to our modern life because acceptance of plastics and sachet nylon packaged water is largely driven by high level of convenience associated with fast lifestyle of the 21 st century (www.augsburg.edu/green/2018/01/17/environmental-impacts-ofbottled-water). With this, current generation should appreciate taking responsibility for the environment while future generations will come to meet preserved environment habitable for mankind (SDG Report, 2019).

The rise in bottled and sachet water production is becoming a commonplace business venture that can spring up in any neighbourhood whenever entrepreneurs identify the opportunity having observed the necessity of water to mankind (Ezeudu \& Ezeudu, 2019) and (www.sbdcnet.org/small-business-research-reports/bottled-water-industry). Governments at all levels have left the provision of portable water in the hands of private sector since the machinery previously used to provide this essential need to the society has long collapsed. Tap water no longer runs in our towns, cities and hinterlands as it used to be back in the 80s. Some 
households and water factories extend tap water points to their neighbourhood in case such house owners have private pole-holes as good gesture while factories use it as social responsibility. In some instance, people in the villages find succour by drinking water from nearby water brooks thereby exposing their lives to water borne diseases. Noting this fact, entrepreneurs decide to meet this need through production and marketing of packaged bottled and sachet water.

Packaged water production and marketing has almost left the environment littered with bottles and sachet nylon waste after the content has been used off (after-end-of-life-use). Apart from that, non-biodegradable nature of the polythene material used in making plastics and sachet nylon has a lasting and damaging effect on the environment (Babayemi et al., 2019; Olarewaju \& Oyebade, 2019) and www.augsburg.edu/green/2018/01/17/environmental-impacts-ofbottled-water). It could impact negatively on mineral quality of natural soil and litter water passage ways thereby causing floods. Notably, large volume of plastics water bottles and sachet nylons enter the environment as waste. These social practices constitute high environmental risk as they negatively affect society both locally and internationally thus represent illegal behaviour that studies have suggested should be grossly legislated against (Willis, Maureaud, Wilcox \& Hardesty, 2018).

The responsibility to conserve, preserve and protect the environment is almost a struggle among stakeholders, then the question that often arise is to: who is actually supposed to take lead in the vanguard? Noting that the impact and dominance of human economic activities are readily manifesting in array of environmental problems e.g. environmental degradation, high temperature resulting from ozone layer depletion, global warming and high occurrence of climatic change with its attendant effects on humanity (Ogunniran, 2018). In this wise, there is now a necessity to take collaborative efforts with all stakeholders acting towards preserving and conserving the environment for the benefit of current and future generations (Romolimi, Brinkley \& Wolf, 2012; cited in Arakawa et al, 2018). In other vein, each stakeholder can take individual initiative with the support of others e.g. partnership i.e investors through investment, employees cooperation, consumers by patronage of firm's products and services practising stewardship etc. In this thinking, Marazzi, Loiselle, Anderson, Rocliffe, and Winton (2020) show support for consumer based-action perspective in addressing plastics waste.

The clamour that business organisations need to engage in business activities beyond regulatory compliance and rational economic benefits by taking lead in environmental stewardship to foster business sustainability is proposed (Gunimaraes \& Sato, 1996). Consumers of productive output are gradually recognising the need to demand that business managers should integrate greening practices into their business system from procurement to production and marketing of products and services in order to stay relevant and sustain their business into the future. The failure of government in some sectors in respect of weakness in regulatory framework, poor laws and policies is plainly exposed. The economic and business activities of enterprises that are supposed to operate in an adequate and stringent regulatory and legislative configurations in such a way that environmental resources are preserved and conserved have flipped into the hands of individuals capitalists/entrepreneurs who explore the commonwealth wrapped in the environment for only economic purpose without any stewardship agenda. In this regards, involvement of any business enterprise in environmental stewardship tends to endear customers, investors, and government to such business endeavour and future generation's strong sense of place (attachment) could therewith be promoted (Arakawa et al, 2018). 
Producers of bottled and sachet water should take up the responsible management of their activities in the environment by engaging in activities that will sustain their business in the long run while they preserve and conserve the environment alongside. Involvement in environmental stewardship has not been entrenched in the operations of the entrepreneurs due to lack of capacity to do so and failure of government to provide framework to drive stewardship activities. In case any organisation is involved in it at all, commitment is poor or activities around it are done haphazardly. Also, government policy towards plastic waste recycling is at its infancy (Bokani, 2019). Justification for any commitment should be demonstrated by giving place to protecting the environment in business budget and implementation which is expected to show in the surrounding communities where water factories are sited. Even level of compliance to cleaner environment from government agencies has not been adhered to jealously, if there is any serious compliance demands at all.

The awareness and concern of government and society generally are gaining momentum day by day as group advocacy is increasing demands on the need to impose a ban on the production of plastics for bottle and nylon sachet water (Federal Ministry of Environment, 2016; Amusa, 2018; Babayemi et al, 2019; The Guardian and Vanguard Newspapers, 2020). The calls and agitations to stop or source for alternative packaging for water in place of plastics and nylon has long commenced in some countries as demonstrated in Rwanda (Babayemi et al ,2019). Sustainable Development Goals (SDG) 12 further emphasizes clearly this call as it states that there is need to ensure sustainable consumption and production pattern in an effort to reduce material footprints (Sustainable Development Goals Report, 2019). It is observed in Sookram (2013) cited in UN Global Compact (2010) that global business community notice that environmental stewardship is extremely critical to business but only a small portion of firms in our market worldwide have taken steps in the direction of genuine stewardship. In an attempt to yield to SDG 12 there is call to reduce our 'material footprints' through conscious and deliberate effort towards reducing, reusing and recycling waste plastics and nylon sachet used in packaged water by engaging in recovery, repossession and recycling activities (Adedugbe, 2017).

In addition, there are rising concerns of eyes sore experience that are already manifesting in high volume and rate at which empty bottles, trash, and sachet nylon waste litter the beach for days after heavy rainfall particularly in the cities. This phenomenon has even increased tourism cost in the hospitality industry because there is need to make beaches attractive to tourists in an effort to clear off the dirt. Streets and neighbourhoods in our State capitals have share in this situation. The convergence of these issues should even serve as motivation (Bennett et al., 2018) for environmental stewardship. Extant literature in environmental stewardship is less empirical (e.g. Bennett et al., 2018; Neilsen et al., 2019 and Ranganadhan, 2018) while few evidence based studies were carried out in the developed economies (e.g Guimaraes \& Sato, 1996; Marazzi et al, 2020). In sum, the study intends to fill this gap by providing answer to the questions that: what effect does environmental stewardship has on business sustainability? What is the most practised stewardship actions among firms in the packaged water business? The objectives of the study are to (i) establish the effect environmental stewardship on business sustainability; (ii) identify the environmental stewardship actions that is most practiced among firms in the packaged water business.

\section{THEORY AND RESEARCH HYPOTHESIS DEVELOPMENT 2.1 Environmental stewardship}

Environmental stewardship is an action that embraces and balances the need of various groups while ensuring natural resources are consistently conserved and used responsibly. In a more apt 
perspective, environmental stewardship can be defined as "the responsible use (including conservation) of natural resources in a way that takes full and balanced account of the interest of society, future generations, and other species, as well as of private needs and accepts significant answerability to society" (Worrell \& Appleby, 2000). It involves firms extending and taking environmental actions beyond economic rationality (Guimaraes \& Sato, 1996). Ruyter, Jong and Wetzels (2009) express that environmental stewardship is a collective responsibility towards the environment which must manifest in organisation's policies, procedures and actions in addressing employees' and customers' relationship. Organisations need to design their operations through taking lead without being pushed by government regulations or customers demands for stewardship activities. For the purpose of this study, it is defined as responsible management of human activity that affects the environment with intention to ensure conservation and preservation of natural resources and values for the future generation's sake in which there is acceptable significant accountability to the society (Welchman, 2012).

It is regarded as deliberate and concerted effort to ensure medium sized firms contribute towards preserving, protecting and managing resource responsibly for the benefit of the environment at large with no coercion to do so. It is recognised as a process that leads to creation of wealth from waste while exploiting resource potential that is in waste plastics bottles and sachet nylon. Existing government policy in the country specifies principles that pushes for preservation of the environment e.g. polluter pays and user pays principles (Federal Ministry of Environment, 2016) and some studies e.g. Banacu, Busu, Ignat and Trica (2019) advocate polluter pay as regulatory mechanism to address recycling issues. These already create platform for environmental stewardship action from the producers' standpoints which sort out to promote business sustainability. Innovatively, environmental problem is better solved by producers and any action in this direction constitutes and tends to expand market opportunity (Arnold \& Neubert, 1997).

\subsection{Stewardship actions}

Stewardship actions include combinations of approaches, activities, behaviours and technologies that are applied to protect, restore or sustainably use the environment as a medium to improve on business processes and gain innovative advantage (Bennett et al., 2018). It is important to plan these actions into firms' activities to further preserve, conserve and protect the environment in order to support business sustainability. Individual firm actions can stem from having waste reduction and management practice that sorts usefully. There can also be a correct and regular waste disposition and then disregard traditional practice common in the less developed nations in the disposition of waste e.g. burning, dumping, littering and land-filling. Firms need to encourage and motivate consumers to separate and pick recyclable items and offer them for sale to recycling firms or engage in waste buy back or waste return scheme. In addition, packaged water enterprises can budget stewardship actions annually and in some instances organisations need to engage in social education and awareness campaign to involve members of the society on the need to responsibly participate in being stewards of the environment. Stern, Powell, and Ardoin (2008); Tidball and Krasny (2011) encourage that environmental education as supporting activity through which the product end users and youth are involved indirectly in environmental stewardship. Government can enforce or encourage and motivate business organisations to integrate and implement polluter pays and user pays principles as part of their business model (Federal Ministry of Environment, 2016). In other words, it is suggested that government needs to make stewardship action part of licensing requirement before business can start operation or permit new product launch (Marazzi et al., 2020). 
In this study, environmental stewardship actions include community engagement, recycling and waste reduction and management activities as suggested areas for research raised in Guimaraes and Sato (1996). Community engagement typicallyconnotes community participation and it is aimed at making the environment meet the aspiration and desire of the local community while using it as means to drive local economy and protect the environment for sustainable business (Wang \& Tong, 2009). Waste in landfill is no longer supportive to society as it hinders sound environmental sanitary culture among people which is a threat to well-being and healthy living. Engagement or participation of community tends to foster social support and constitutes part of the role business need to play in changing society orientation towards waste. Individual persons, homes and offices already witness the menace and unhealthy nature of waste to the society and environment. They can collectively and individually accommodate culture of stewardship as way of life. Waste sorting tends to invariably reduce quantity of waste disposed and the practice can serve as a means of providing little economic income to homes and support less privileged families in the society (www.ashawaconsultsltd.com/community-participation-in-solid-wastemanagement/).

Recycling activities are important processes to maintain and improve man's social, physical ambiance and life which can influence behaviour. Waste cannot absolutely be removed from human life but efforts should be towards reduced and manageable waste in a manner that is not inimical to human existence. Recycling is a collection process that involves gathering of waste items that ordinarily is seen as trashes and reprocess them into new product for value creation (https://www.epa.gov/recycle/recycling-basics). This requires corporate and individual behavioural change, policies and adoption of new production processes to facilitate it. More importantly, recyclable items like plastics water bottles and sachet nylons (Ezeudu \& Ezeudu, 2019) after end-of-use-life need to be deposited and collected from our homes, streets and offices for the purpose of reprocessing them. Its possibility is relevant and rests on collaborative efforts among all stakeholders.

Waste reduction and management activities (e.g. reducing, collecting, sorting of wastes) demand that we rethink our production and consumption pattern to properly identify items that we can reuse to reduce waste. The common littering and waste burning among others is no longer desirable. There is need to feature embedded product responsibility (Lewis and Sonneveid, 2019; Quartey, Tosefa, Danquah and Obrsalova, 2015) in our waste reduction and management practices to preserve the environment. It gives everyone role to play in the management of human activity that revolves around waste. Neilsen et al. (2019) lament the lower rate of waste management process compared to rising speed in plastics production thereby confirms rising rate in plastics pollution as there is insufficient and ineffective waste management system. This again emphasises the level of unethical waste reduction and management practices in our society particularly developing nations. However, it opens business window to scavengers but constitutes toxic health hazard to these individuals. Epstein (1995) identifies and supports corporate environmental strategies for curtailing environmental impact of business activities which include recycling, waste reduction and life cycle assessment and its need to form part of business model to addressing waste issues. This points to necessity why this should be confirmed by examining its evidence-based relevance to sustainable business. 


\subsection{Business sustainability}

Simply, business sustainability is outcome effect that results from conscious and deliberate efforts of business organisations as reasons to the pursuance of certain business actions in order to survive and make profit continuously (Schalteggar \& Burritt, 2005). Pursuance of environmental stewardship can engender and achieve business sustainability which is an end goal that promises an assured and secured future for the society (Environmental Protection Agency, 2005). Guimaraes and Sato (1996) recognise it as business benefits derived when firms seek environmental improvements or ensure environmental sensitivity. Mar (2013) considers it a 'strategy that priotises long term survival of a business and with its connection to ecological, economic, social and cultural systems'. Environmental stewardship is an effort that comes out of choice that enterprises engage in to keep business operations on without being endangered with the waste coming from business productive activities. The effort can promote firms' image and create loyal customers which possibly make the company more competitive and sustainable as long as it exists. By this, business enterprises create a link that serves as meeting point for the environment and the people (society) in such a way that it is not lopsided and endanger any part. Business sustainability involves using fewer resources and improving the community where organisations operate (Arnold \& Neubert, 1997). Ngwakwe (2008) and Elkington (1997) affirm that business sustainability principally resides in business orientations that are captured in economic, environmental and social performance of any enterprise. In the light of the above discussion, it is hypothesised that:

Hypothesis 1. Environmental stewardship actions do not have significant effect on business sustainability

In the tragedy of the commons as underpinning theory for the study, Hardin (1968) argues that if individuals are given the chance to overuse a common property, they will use it in order to realize their ultimate personal benefits. If every person does this, common property quickly becomes overused and damaged (Hardin, 1968). Presently, the circumstance is already manifesting in the way atmosphere, land space and waterways are used with minimal or no deliberate plan to preserve them for longer use. Buchholz, Marcus and Post (1992) further raised a concern that companies' environmental total cost as a result of consistent usage of the environment (being the source of resources) often outweigh the benefits to the society. In this regard, firms need to balance its economic interest with the environment and societal benefits in bid to stimulate congruence that promotes business continuity. The balance of business and environmental benefits towards mutual consequences in the course of resource usage has high possibility of promoting business sustainability.

The danger and condition of the natural environment presently do not support the position of Hardin (1968). Collective and mutual position where business produces goods and services to conserve and preserve environment with a perspective of being its steward tends to prolong business live and satisfies all interested parties. Further, it is suggested that business managers are to take responsible actions for their orgainsational effects that perpetually address stakeholders welfare (Hernandez, 2008).

The opinion in numerous parlance sets the centre stage for discussion on the issue of environmental stewardship. However, the dearth of empirical evidences is so pronounced to further support the debate in this study. Sookram (2013); and Babayemi et al. (2019) advocate for need to embrace and encourage environmental attitude to engender sustainability in business and promote responsible use of items/resources like plastics and nylon in our economy. 
Guimaraes and Sato (1996) draw attention of business managers to reasons for integration of environmental stewardship ideals into their business model as a lot of business benefits abound which include (i) strengthening company image (ii) less material waste (iii) helpful in avoidance of fines (iv) increased customers loyalty. Further, the study also compares firms that practise environmental stewardship in USA with Pacific Rim nations and observe that greater business benefits are experienced by companies that engage more in it than firms that have less involvement. In this wise, the study concludes that companies with high degree and active involvement in environmental stewardship activities such as taking environmental actions based on values, consistently going beyond regulatory requirements, prioritising environmental responsibility at least in parity with financial profitability and beyond economic rationality have likelihood of producing/deriving more business benefits than companies that only comply with regulations and involve in rational environmental actions.

Quartey, Tosefa, Danquah and Obrsalova (2015) identify various strategies that have been well practised in some western economies like Germany and Sweden that produced success for business sustainability of packaged water business among others. Some of such strategies include deposit-refund system/waste buy back, kerbside collection system and bring system which is seen to be extended producers responsibility that is viewed as integrated mechanism to handling waste issue. These result into a win-win strategy for all stakeholders. The adoption of these strategies assists least developed country like Ghana as shown in the study. The study itemizes scenarios such as producer recovery model which consists of consumer-retailer waste collection and route back system. Also mentioned is a state run recovery model that integrates producer-state partnership in the waste recovery and recycling exercise. It is recognised that this can only work in a transparent condition where there is sound accountability to common pooled resources. However, it corroborates the concern raised in the study that corrupt practice can frustrate the state system hence need to allow it to run on private based platform.

The elements of environmental stewardship (e.g. actors, capacities and motivation) are described comprehensively with suggested integrative analytical model that can facilitate productive and realistic insight into environmental policies and programs with the aim to drive sustainability in the society (Bennett, Whitty, Finkbeiner, Pittman, Bassett, Geleich \& Allison, 2018). Arakawa, Sachelera and Shandas (2018) note environmental stewardship as tool to address community cohesion and cultivate meaningful engagement that promotes and engenders environmental improvements. This tends to enhance individual concern and collective community building that preserves and protects the environment with a view to strengthen sense of belongingness, identity and commitment among people within various geographical setups. However, it will be more deepen and sense making to observe these in actual practice among stakeholders. In other words, analytical and theoretical orientation regarding environmental stewardship is not sufficient for conservation and protection of the environment though it creates awareness and educates the society.

Sookram (2013) observes that little below average among organisations' managers have less interest in care for the environment in which they are considered as having anti-environmental attitude. While little above average appreciate commercial interest over environmental issues then some have moderate or vice versa attitude towards the environment. Promotion of stakeholder approach that tends towards avoidance of these inconsistencies and uncertainties is suggested. Further, the study acknowledges that formidable regulatory framework that offers businesses incentives is necessary in a bid to address environmental issues. This is an effort to build environmental attitude and serve interest groups better through balancing the link between social progress and economic growth in environmental stewardship actions. 
Mojekeh and Eze (2011) argue that problem of sachet nylon and plastic water bottles waste is not really with waste itself after the use of its water content but it is poor attitude among consumers. There is limited understanding of the importance of recycling techniques management and correct disposal among water producers which accounts for more environmental impacts of production and sales of sachet water in Nigerian commercial cities. This study merely points out factors accounting for the environmental impacts of sachet nylon waste. It does not reveal pathway to creating an insight on the essence of stewardship since environmental vulnerability is clear from actions of consumers and producers of both sachet and plastic bottle water.

Gbadeyan and Omolekan (2015) discover that green marketing is not common to consumers as products manufacturers have not really lived up to expectation. They have not made much effort to recover waste from the consumers hence the high rate of environmental degradation. Noting the fact, production of eco-friendly products is not possible in the short term then organisations are supposed to take stewardship practice to ensure business sustainability in the sector. In this regard, stewardship of the products' remnants and packaging waste on behalf of the society with the involvement and partnership of all stakeholders (e.g. consumers, producers, community and government etc.) tend to create room for sustainable business.

Ezeudu and Eweudu (2019) discuss framework that supports circular economy model which notes waste (plastics and sachet nylon) as resource that can further create employment. It can also make companies more competitive in solid waste management rather than the current prevalent linear economy model that disposes waste without creating wealth from it. The study adds credence to the position of environmental stewardship in which water packaged producers are expected to take responsibility for end-of-life-use of its product. This ideology draws its potency from producer pays and user pays principles (Federal Ministry of Environment, 2016) but there is weak implementation framework to make it practicable among firms. In the light of this, firms' steward initiatives tend to serve economic and social benefits for the entire society.

Nielsen et al. (2019) conclude that plastic flows (e.g. production, consumption, waste management and pollution) and plastic objects (e.g. bags, bottles, microplastics, and single-use plastics) should respectively be addressed comprehensively and specifically in a way that policy responses help to achieve sustainable plastics sector. The study further advocates for attention to more other pressing environmental issues (e.g. climatic change and overfishing) rather than overbearing concentration on plastics pollution as currently practised. The study is also a review with no empirical analysis. However, significant efforts in the area of policy initiatives and global agreements among industries and economies in relation to plastics are well highlighted to foster strong stakeholders' interest.

Ruyter, Jong and Wetzels (2009) conclude that environmental stewardship positively influence customer satisfaction. This results usually from the antecedent of the stewardship perception of the customers from the employees within-team where there is autonomy and supervisory support. While there is negative effect on sales that is accounted for by between-team consensus due to past sales. This is the expression in differential team environmental stewardship in business to business set-up which signifies need for study along business to customer domain. It is noted in the study that past and antecedent responsible actions often serve as prelude to consequences that follow which reflects in performance parameters - customer satisfaction and sales.

Marazzi et al. (2020) conclude and suggest that consumers should be incentivised to support behavioral change that engenders proper and correct disposal of plastic waste. Again, efforts to 
improve innovative approaches that promote personal appreciation for the environment among consumers is needed to enhance new attitude towards plastic waste. In other direction, people need to reduce usage of plastic water bottles and imbibe reusable bottle culture in their daily lives. Also, the study advocates support for increased legislation, novel recycling technologies and product innovation. These actions among others from consumer-based perspective as shown in the study should bring about reduced use in single-use products such as plastic bottles and sachet nylon.

Ngwakwe (2008) concludes that a relationship exits between environmental responsibility and firm performance in which investment in waste management, employees health and safety practice and community development would increase firm's return on total assets in the long run. In the same vein, the practices portend higher opportunity for reduction of fines, penalties and litigation between firms and host communities thereby enhance corporate image and promote customers' patronage of firms' goods and services. The discussion above is hereby conceptualised below:

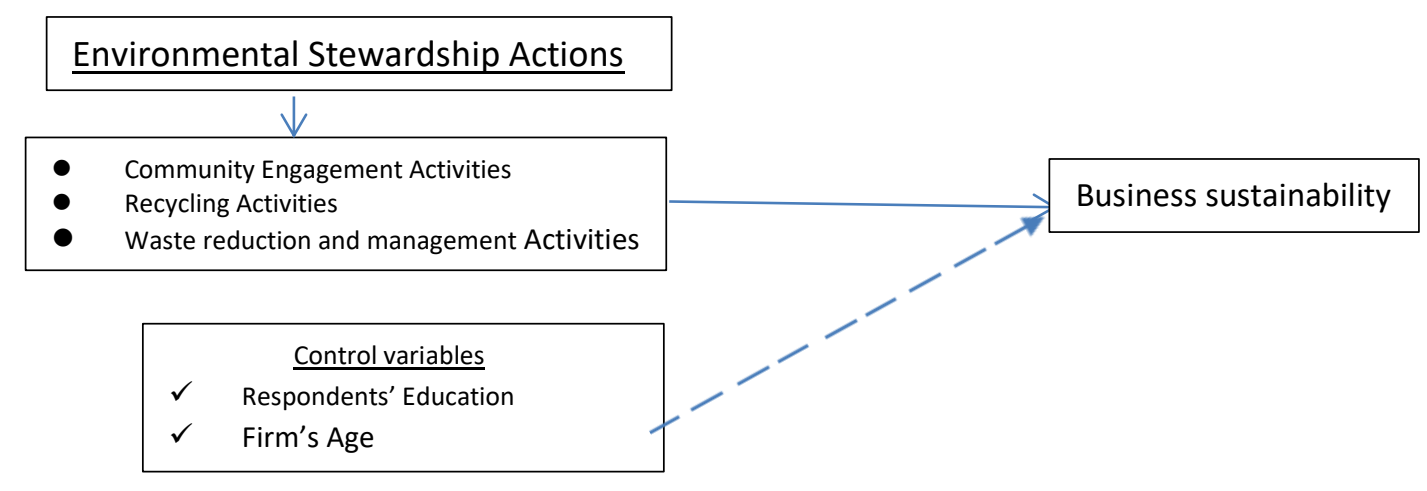

Figure 1. Conceptual Framework

Source: Authors' conceptualisation, 2020

\section{METHOD}

The study employs research survey in which data are collected through questionnaire from water factories owners and their managers respectively. Purposive sampling technique was used as the water packaged industry is among others most bedeviled with much waste streams in its value chain. Registered water packaging companies that are members of Association of Table Water Producers (ATWAP) in southwest states, Nigeria were selected. They are viewed as actors in environmental stewardship (Bennett et al.,2018) based on their activities in packaged water value chain. The focus was on Ibadan metropolis, Oyo State; Ikorodu area of Lagos State; and Sango-Ota, Ogun State. These areas are among the major places that have large concentration of residents households and ATWAP members (Survey report, 2020). ATWAP members who indicated interest to participate were surveyed and questionnaire administered. The target population for the study were all members of ATWAP in the three states in southwest, Nigeria. Members who indicated interest and consent to participate in the study form the sample for data collection purpose. In this regards, 230 respondents were contacted and only 205 respondents showed interest and this represents $89.13 \%$ respondents of the total respondents. The total respondents were randomly approached in the selected areas to whom questionnaire were given to fill. In other words, a questionnaire per company was administered. The companies include sachet or plastic bottled water producers and/or both which are small and medium sized enterprises largely because of the number of persons in their workforce. One 
hundred and ninety one (191) copies of the questionnaire were retrieved out of the questionnaire distributed which represents $93.17 \%$ of those that indicated interest of participation in the study.

Each question is subjected to reliability test and results show cronbach's alpha of .682, .782, .685 and .786 for community engagement, recycling activities, waste and reduction management, and business sustainability respectively having used twenty copies of questionnaire that contain all questions in a plot survey before the main survey. The cronbach's alpha scores are all above 0.6 which confirm that they are reliable ( Hair Jr., Black, Babin, Anderson \& Tatham, 2006). This affirms no question is deleted from the list of questions raised for the study, which means they all address the purpose the questions are meant for. Face validity conducted confirm the questions are valid for the study.

The questions in the questionnaire follow a five point likert scale to which environmental stewardship proxy are community engagement, recycling and waste reduction and management activities with their respective questions. To measure: (a) community engagement, eight (8) questions with sample item such as (i) my company offers to pick filled up waste bins from our surrounding neighbours once a while, three weeks or months to clean up the environment, (b) recycling activities, seven (7) questions with sample item such as (i) my company collaborates with retail business owners/customers/consumers in waste deposit return scheme of clean empty bottle/sachet into waste bin close by to make them more accessible for recycling and (c) waste reduction and management, eight (8) questions with sample item such as (i) my company involves in burning of waste bottle and sachet nylons. Respondents were asked to indicate the extent of practice of each of the activity. To measure business sustainability, seven (7) questions that bothers on the three sustainability dimensions were raised with sample item such as (i) economic benefit in form of increased profit becomes more realistic. The average of each response was determined and obtained. Descriptive statistics and multiple regression analysis were utilised to determine (i) the most practiced of the stewardship activities and (ii) the effect of environmental stewardship on business sustainability. To this end, the model that address the analysis is thus stated:

\section{BS $=\mathbf{f}($ CEA, RA, WRMA $)$}

Where:

BS = Business sustainability

CEA $=$ Community engagement activities

RA $=$ Recycling activities

WRMA = Waste reduction and management activities

Then it becomes:

$\mathbf{B S}=\beta_{0}+\beta_{1} \mathbf{C E A}+\beta_{2} \mathbf{R A}+\beta_{3} \mathbf{R W M A}+\mathbf{E t}$ model (1)

Where:

$\boldsymbol{\beta}_{0}=$ constant coefficient and slope of the model

$\boldsymbol{\beta}_{1}-\boldsymbol{\beta}_{3}=$ coefficients of Community engagement activities, Recycling activities and Waste reduction and management activities

$\mathbf{E t}=$ error term

In order to control for personal and firm's attributes in the surveyed companies, level of education of respondents (owners while managers proxy for owners) and age of the firms are included in the model to modify model 1 which thus becomes model 2 and states as:

BS $=\beta_{0}+\beta_{1}$ CEA $+\beta_{2} R A+\beta_{3} R W M A+\beta_{4} R_{\text {espdt }}$ Edu + Firm $_{\text {Age }}+$ Et ............model (2) Model 2 gives consideration to these attributes to address robustness to test for possible significant influence of these control variables along the predictors stated in model 1 . In this wise, firm's age and Respondents' education are included to control for their effects. 


\section{RESULTS}

The result in Table 1 indicates that there is low level correlation among the independent variables which show that they are not related. In this wise, no multicollinearity exists among the predictors as there is no variable with correlation that is above 0.548 which is far below 0.7 threshold. The variables are also significant at $p$-value $<0.05$. The analysis shows a variance inflation factor (VIF) that ranges between 1.478 and 1.693 which are below benchmark of 5 or 10 indicating that multicollinearity does not exist among the constructs (Hair, Anderson, Totham, \& Black, 1995; Ringle, Wende, Becker, 2015). This confirms that they are appropriate for the model formulated.

\begin{tabular}{ccccccc} 
& \multicolumn{6}{c}{ Table 1. Correlations Matrix and } \\
Variables & Mean & SD & BS & RA & CEA & WRMA \\
& 3.3156 & .74646 & 1.000 & $.455^{* *}$ & $.271^{* *}$ & $.481^{* *}$ \\
BS & 2.9858 & .76673 & $.455^{* *}$ & 1.000 & $.548^{* *}$ & $.540^{* *}$ \\
RA & & & & & & \\
CEA & 2.6767 & .70258 & $.271^{* *}$ & $.548^{* *}$ & 1.000 & $.445^{* *}$ \\
WRMA & 3.0262 & .66328 & & & & \\
& & & $.481^{* *}$ & $.540^{* *}$ & .445 & 1.000
\end{tabular}

Table 1 shows the correlations matrix and descriptive statistics. $\mathrm{N}=191$. (a) Dependable variable $=$ Business Sustainability; (b) Predictors: CEA = Community Engagement Activities; RA = Recycling Activities; and WRMA = Waste Reduction and Management Activities; (c) Significant at $* *=p$-value $<0.05$

Source: Authors' compilation, 2020.

Table 1 also shows that waste reduction and management (WRM) has the highest mean value (3.0262). It is an indication that proper and correct disposal and reuse of waste are gradually inculcated and imbibed among businesses. It is pertinent to note that activities revolve more around WRM than others. In addition, recycling activities with mean value of 2.9858 proves that businesses support the practice to an extent as shown in this study. However, community engagement with the lowest mean value is not practiced as much as others. In this respect, it shows that motivation to business owners to build capacity in order to strengthen practices in CEA tend to provide input and create cheaper avenue that can help organisation achieve business sustainability.

Table 2 shows results of the study that there is relationship between environmental stewardship and business sustainability. The correlation is moderate and slightly above fifty percent as depicted in Table 2 (see Model 1). Individually, recycling and waste reduction and management activities are positively significant at $p$-value $<0.05$ which are the common practices among the small and medium enterprises owners and have relationship with business sustainability. However, the community engagement activities are not significant at $\mathrm{p}$-value $>0.05$. Further, environmental stewardship contributes 27.5 percent to the variation in business sustainability. It demonstrates the extent of development present in the practice of environmental stewardship among organisations in the water packaging industry. The hypothesis that environmental stewardship actions do not have significant effect on business stewardship is not supported. In this regard, the alternative hypothesis is supported. The model formulated is fit to predict the effect of environmental stewardship on business sustainability. Model fitness is confirmed at F-statistics $=25.012$ and significant at $\mathrm{p}$-value $<0.05$ which ascertains that environmental stewardship actions have significant effect on business sustainability. 
Table 2. Regression Analysis of the Environmental Stewardship and Business Sustainability

\begin{tabular}{|c|c|c|c|c|}
\hline Variables & \multicolumn{2}{|c|}{ Model 1} & \multicolumn{2}{|c|}{ Model 2} \\
\hline Main variables & Beta & t-value & Beta & t-value \\
\hline CEA & -.045 & -.557 & -.029 & -.363 \\
\hline RA & .285 & $3.646 * *$ & .285 & $3.661 * *$ \\
\hline WRMA & .385 & $4.552 * *$ & .373 & $4.424 * *$ \\
\hline Constant & 1.419 & $5.955 * *$ & 1.151 & $4.180 * *$ \\
\hline \multicolumn{5}{|c|}{ Control variables } \\
\hline FirmAge & & & .017 & .021 \\
\hline RespdtEdu & & & .083 & .111 \\
\hline $\mathrm{R}$ & .536 & & .548 & \\
\hline $\mathrm{R}^{2}$ & 286 & & .300 & \\
\hline $\mathrm{AdjR}^{2}$ & .275 & & .281 & \\
\hline F-statistics & 25.012 & & 15.882 & \\
\hline p-value & $\leq 0.05$ & & $\leq .0 .05$ & \\
\hline
\end{tabular}

Table 2 shows the regression analysis of the environmental stewardship and business sustainability.

$\mathrm{N}=$ 191. (a) Dependent variable: $\mathrm{BS}=$ Business Sustainability; (b). Predictors: CEA = Community Engagement Activities; RA = Recycling Activities; and WRMA = Waste Reduction and Management Activities; (c) Control variables: FirmAge and RespdtEdu = Respondents' Education; (d) Significant at $* *=p<0.05$.

Source: Authors' compilation, 2020.

The result in model 2 where the control variables are included improves the contribution of predictors to the dependent variable. This further explains that the respondents' education and age of the firms in operations tend to afford organisations the experience to appreciate and appropriate the relevance of environmental stewardship. It confirms robustness of model 2 though the addition of firm's age and respondents' education as firm attributes do not have any significant effect on business sustainability. In addition, more than $64.4 \%$ of the respondents has first degree equivalent as minimum qualification which points to a fact that they have knowledge and information capacity to interpret issues in the environment to their advantage (Appendix 1). This result asserts the studies of Guimaraes and Sato (1996); Marazzi, Loiselle, Anderson, Rocliffe and Winton (2020); Ranganadhan (2018); and Ruyter, Jong and Wetzels (2009).

\section{DISCUSSION AND CONCLUSION}

It is observed from the study that there is some levels of collaboration between organisations in the packaged water industry and waste recycling organisations. Plastics and nylon waste generated within factories are properly gathered and collected for recyclers' uptake to avoid government sanctions (penalties and fines) where these activities are not in practice. The interactions with owners and managers also confirm that local government authorities officials ensure they at times conduct sanitation visit to confirm compliance. In other words, waste reduction and management is common but the usual practice is unethical and inimical to human existence. The study shows that government is yet to encourage organisations through incentives and tax rebates to spur them to embrace more ethical practices such as reuse of empty bottles for local food items packaging like palm oil and wine, vegetable oil, Zobo drinks among others. Mostly, the common practice is waste burning and dumping at dumpsite which they consider to be a major means to steward the environment but unsustainable.

In another vein, some managers of packaged water companies affirm that people in some medium sized farming and construction businesses reuse waste sachet nylon at their nursery 
farmers to prepare and manage their seedlings before main plantation. In addition, those in construction business reuse waste sachet nylon for prevention of undergrowth of weeds and grasses in household paving stones layout in order to minimise cost for most lower class and some middle income earners. These practices among others demonstrate that appreciation of environmental stewardship is possible in this part of the world and tends to help business sustainability.

Community engagement activities are not well embraced. Poor engagement in these activities is weak among organisations. The study notices that incentive, education and awareness to drive this culture is alien to the industry. The prevalent and current experience of waste litter in our streets and communities confirms the position as shown in the analysis. Generally, indecent disposal of waste bottles and sachet nylon is pervasive among people which may be blamed on government institutions for not implementing stringently policy such as user pay (Federal Ministry of Environment, 2016). In other words, polluter pay policy might have even spur organisations in the water packaging industry to initiate culture that can motivate final and endusers' interest to join the vanguard that stewards the environment by engaging actions such as disposing waste correctly and properly for recycling purposes.

The findings in the hypothesis that controlled for the effect of firm age and respondents' education account for slight increase in variance of business sustainability. But at individual level, none of the control variables account for any variance in business sustainability which means it is only combined effect on the dependent variable that produces variance as shown in the study. In other words, individual respondent and firm effects will help to develop better insight into the contribution of environmental stewardship on business sustainability in order to enhance enterprise continuity and competitiveness.

Environmental stewardship promises a lot of benefits both for organisations, government and society as a whole. Organisations tend to earn support of government institutions where the practice is embedded in business model of any enterprise. In another dimension, consumers patronage is high with potential to enhance and ensure business continuity and competitive advantage well above rivals (Guimaraes \& Sato, 1996). This condition will guarantee trust of the future generations in that firm's offerings (goods and services). The study confirms the relevance and strategic connection of environmental stewardship to organisations' agility. However, that $84.3 \%$ of the companies surveyed have only existed for less than ten years as revealed in the study show the early stage of most of the organisations (Appendix 1). On this note, involvement in environmental stewardship actions could have possibly created unique niche and endear the organisations to their customers more beyond offering packaged water to the market. Again, owners' presence in the management of the organisations' operations also creates room for quick decision to embrace the strategy as plausible and worthwhile. The findings from the current study establish novel insights into the environmental stewardship and business sustainability link. The study also provides empirical evidence which previous studies do not dive into (Bennett et al., 2018; and Nielsen et al., 2019).

\section{MANAGERIAL IMPLICATIONS}

The emphasis on recycling and waste reduction and management is what managers of organisations need to find ways to consider more through engaging in proper coordination of the activities to further harness them for optimal benefits. Particularly, waste bottle reuse is gradually gaining acceptance among micro business owners. There is need for campaign to encourage more reuse through media orientations that promotes customers' trust in the product 
content. In addition, hygienic standard should be introduced both from government institutions and the players' trade association in order to enhance customers' confidence in the product content and packaging.

\section{LIMITATION AND SUGGESTIONS FOR FUTURE STUDIES}

The study focuses only on packaged water industry which limited the scope. This also raises need to take caution not to completely generalise the result to other sectors in the economy that generate hardware waste items from their operations e.g. electrical and electronics, telecommunications and motor parts. It is therefore plausible to extend future study to these industries. The main constructs and control variables may be subjected to other research analysis techniques to unravel whether the results will be consistent with what is obtained from the current study. Government policies on environmental stewardship actions should be examined to determine their effectiveness.

\section{ACKNOWLEDGEMENTS}

The authors would like to thank the following individuals that joined in the data collection exercise and they are: Babatunde Olayiwola (Secretary, ATWAP, Akobo), Niyi Oladele, and our undergraduate and graduating students Fasina Damilare all in Ibadan Metropolis, Kehinde Aromona, Ota; and Oreoluwa Oyedeji, Ikorodu. Also, we thank O. J. Omolekan and O. D. Omodara for providing valuable comments on the earlier versions of the paper.

\section{REFERENCES}

Arnold, M. \& Neubert, B (1997). Competitiveness Project Summary.The Management Institute for Environment and Business (MEB), A Program of the World Resources Institute (WRI), Washington, DC 20006, 1-18.

Amusa, T.V. (June, 25, 2018) The Guardian Newspapers. Anti-plastic pollution campaign as big tep at mitigating climate change. Retrieved from https://guardian.ng/property/antiplastic-pollution-campaign-as-big-step-at-mitigating-climate-change/

Arakawa, S., Sachdeva, S., \& Vivek Shandas, V. (2018). Environmental Stewardship: Pathways to Community Cohesion and Cultivating Meaningful Engagement. Springer International Publishing, 1-24. DOI: 10.1007/978-3-319-53121-2_37-1

Babayemi, J.O., Nnorom, I.C., Osibanjo, O \& Weber, R. (2019). Ensuring sustainability in plastics use in Africa: consumption, waste generation and projections. Environmental Sciences Europe, 31(60), 1-20 https://doi.org/10.1186/s12302-019-0254-5

Banacu, C.S., Busu, M., Ignat, R., \& Trica, C. L. (2019). Entrepreneurial Innovation Impact on Recycling Municipal Waste. Panel Data Analysis at the EU Level. MDPI- Sustainability, 11 (5125) 1-13. doi: 10.3390/su11185125.

Bennett, N. J., Whitty, T. S., Finkbeiner, E., Pittman, J., Bassett, H., Geleich, S., \& Allison, E.H. (2018). Environmental Stewardship: A Conceptual Review and Analytical Framework. Environmental Management (61),597-614. https://doi.org/10.1007/s00267017-0993-2

Bokani, U.A. (2019). Current Status of Waste Management and Plastic Management in Nigeria, Policy and Industry Aspects. Director, Federal Ministry of Environment, Nigeria. 1-24.

Buchholz, K.A., Marcus, A.A., \& Post, J.E. (1992). Managing Environmental Issue: Acasbook, Englewood Cliffs, NJ: Prentice-Hall, Inc.

Charter, M., \& Polonsky, M.J. (1999). Greener Marketing: A Global Perspective to Greening Marketing Practice, (2ed.), Greenleaf Publishing, Sheffield, UK. 
Elkington, J. (1997). Cannibals with forks; The Triple Bottom line of 21st Century Business, London. Capstone.

Environmental Protection Agency (2005). Everyday Choices: Opportunities for Environmental Stewardship, EPA Innovation Action Council, 1-26.

Epstein, M.J. (1995). Measuring Corporate Environmental Performance: Best Practices for Costing and Managing Effective Environmental Strategy. New Jersey. IMA/McGraw Hill.

Ezeudu, O.B., \& Ezeudu, T.S. (2019). Implementation of Circular Economy Principles in Industrial Solid Waste Management: Case Studies from a Developing Economy, Nigeria Recycling, 4(42),1-18; https://doi.org/10.3390/recycling4040042

Federal Ministry of Environment (2016). National Policy on the Environment: Revised, 1-58.

Gbadeyan, R.A. \& Omolekan, O.J. (2015). Relevance of Green Marketing on Environmental Degradation: An Empirical Study of Consumers' of Green Products in Benin- City, Nigeria. University of Mauritius Research Journal, 21: 1-25.

Guimaraes, T. \& Sato, O. (1996). Benefits of Environmental Stewardship: Comparing U.S. and Pacific Rim Companies. Journal of Transnational Management Development, 2(3), 59-80

Hair Jr., J.F., Anderson, R.E., Tatham, R.L., \& Black, W.C. (1995). Multivariate Data Analysis (3ed.). New York: Macmillan.

Hair Jr., J.F., Black, W.C., Babin, B.J., Anderson, R.E., \& Tatham, R.L. (2006). Multivariate data analysis (6ed.). New Jersey: Prentice-Hall, Inc.

Hardin, G. (1968). The tragedy of the commons. Science, 162(3859), 1243-1248.

Environmental Impacts of Bottled Water (2018). Retrieved from https://www.augsburg.edu/green/2018/01/17/environmental-impacts-of-bottled-water https://www.sbdcnet.org/small-business-research-reports/bottled-water-industry

Hernandez, M. (2008). Promoting stewardship behavior in organizations: a leadership model. Journal of Business Ethics, 80, 121-128. doi:10.1007/s10551-007-9440-2.

Jambeck, J., Hardesty, B.D., Brooks, A.L., Friend, T., Teleki, K., Fabres, J., Beaudoin, Y., Bamba, A., Francis, J., Ribbink, A.J., Baleta, T., Bouwman, H., Knox, J., \& Wilcox, C. (2018). Challenges and emerging solutions to the land-based plastic waste issue in Africa. Marine Policy, 96, 256-263

Lewis, H. \& Sonneveld, K. (2003), Unwrapping the Discourse: Product Stewardship and Sustainability in the Australian Packaging Industry,1-13.

Marazzi, L., Loiselle, S., Anderson, L.G., Rocliffe, S., \& Winton, D.J. (2020), Consumer-based actions to reduce plastic pollution in rivers: A multi-criteria decision analysis approach. PLoS ONE 15(8), e0236410, 1-15. https://doi.org/10.1371/journal. pone.0236410

Mercer, D. (2004). Tourism and resource management. In C. Hall, A.Lew \& A. Williams (Eds.) A Companion to tourism, Oxford, UK: Blackwell Publishing. (pp. 462-472).

Menon, A., \& Menon, A. (1997). Enviropreneurial marketing strategy: The emergence of corporate environmentalism as market strategy. Journal of Marketing, 61(1), 51-67. https://doi.org/10.2307/1252189

Mojekeh, M.O. \& Eze, P.A.O. (2011). The Environmental Impact of Production and Sales of Sachet Water in Nigeria. African Research Review: An International Multidisciplinary Journal, Ethiopia, 5(4), 479-492.

Nielsen, T.D., Hasselbalch, J, Holmberg, K \& Stripple, J. (2019). Politics and the plastic crisis: A review throughout the plastic life cycle.WIREs Energy and Environment published by Wiley Periodicals, Inc.

Ngwakwe, C.C. (2008). Environmental Responsibility and Firm Performance: Evidence from Nigeria.World Academy of Science, Engineering and Technology International Journal of Social, Behavioral, Educational, Economic, Business and Industrial Engineering, 2(10), 1055-1062.scholar.waset.org/1999.1012811. 
Ogunniran, B.I. (2018). Ozone Layer Depletion and Climate Change in Nigeria - Problems and Prospects: A Review. Global Journal of Research and Review, 5,1:2

Olarewaju, O.O. \& Oyebade, A.D. (2019). Environmental Menace of Plastic Waste in Nigeria: Challenges, Policies and Technological Efforts.World Environmental Conservation Conference, 321-333. Retrieved from: https://www.researchgate.net/publication/ 335989265

Ranganadhan, S. (2018). Environmental Stewardship for Sustainable Business: A Review in Global Perspective. International Journal of Advance Research and Development, 3(1) 200-204.

Ringle, C. M., Wende, S. \& Becker J. M. (2015). SmartPLS 3 Bonningstedt: SmartPLS. Retrieved from http://www.smartpls.com

Ruyter, K., Jong, A., \& Wetzels, M. (2009). Antecedents and consequences of environmental stewardship in boundary-spanning B2B teams. Journal of the Academic. Marketing Sciences, 37, 470-487. doi 10.1007/s11747-009-0138-0

Schalteggar, S. \& Burritt, R.L. (2005). Corporate Sustainability in Folmer H. and Tietenberg T The International Yearbook of Environmental and Resource Economics 2005/2006. A Survey of Current Issues Cheltenham, Edward Elgar Publishing, 185-222

Stern, M.J., Powell, R.B., \& Ardoin, N.M. (2008). What Difference Does It Make? Assessing Outcomes From Participation in a Residential Environmental Education Program. $J$ Environ Educ, 39:31-43. https://doi.org/10.3200/JOEE.39.4.31-43

Tidball, K. \& Krasny, M. (2011). Urban environmental education from a social-ecological perspective: conceptual framework for civic ecology education. Cities Environ CATE 3(1),20. http://escholarship.bc.edu/cate/vol3/iss1/11.

United Nations Global Compact (2010). Environmental Stewardship Strategy: Overview and Resource for Corporate Leaders, United Nations, New York, USA. 1-32.

Wang, H. \& Tong, M. (2009). Research on community participation in Environmental Management of Ecotourism. International Journal of Business and Management, 4(3), 131-135.

Welchman, J. (2012). A Defence of Environmental Stewardship. Environmental Values, The White Horse Press, 21: 297-316. doi: 10.3197/096327112X13400390125975

Williams, P.W., \& Ponsford, I.F. (2008). Confronting tourism's environmental paradox: Transitioning for sustainable tourism. Futures, 41(6), 396-404.

Willis, K. Maureaud, C. Wilcox, C. \& Hardesty, B.D. (2018). How successful are waste abatement campaigns and government policies at reducing plastic waste into the marine environment? Marine Policy, 96: 243-9.

Wong, P. (2004). Environmental impacts of tourism. In Hall, C., Lew, A., \& Williams, A. (Eds.) A companion to tourism, Oxford, UK: Blackwell Publishing (450-461).

World Tourism Organization. (2008b). From Davos to Bali: A Tourism contribution to the challenge of climate change[PDF]. Retrieved from http://sdt.unwto.org/sites/all/files/ docpdf/ccbrochdavbalmem bbg.pdf

Worrell, R., \& Appleby, M. C. (2000). Stewardship of natural resources: definition, ethical and practical aspects. Journal of Agricultural and Environmental Ethics, 12(3), 263-277.

Quartey, E.T., Tosefa, H., Danquah, K.S.B. \& Obrsalova, I. (2015). Theoretical Framework for Plastic Waste Management in Ghana through Extended Producer Responsibility: Case of Sachet Water Waste. International Journal Environmental Research and Public Health, 12, 9907-9919; doi:10.3390/ijerph120809907

Environment: FG prepares bill to ban plastic production. (2020, Feb., 24).Vanguard Newspapers. Retrieved from https://www.vanguardngr.com/2020/02/environment-fgprepares-bill-to-ban-plastic-production/ 


\section{Appendix 1}

Table 1a Respondents' Sex

\begin{tabular}{|c|l|r|r|r|r|}
\hline \multicolumn{2}{|c|}{ Sex } \\
\hline \multicolumn{2}{|c|}{ Gender } & Frequency & Percent & Valid Percent & $\begin{array}{c}\text { Cumulative } \\
\text { Percent }\end{array}$ \\
\hline \multirow{3}{*}{ Valid } & Male & 110 & 57.6 & 57.6 & 57.6 \\
\cline { 2 - 6 } & Female & 81 & 42.4 & 42.4 & 100.0 \\
\cline { 2 - 6 } & Total & 191 & 100.0 & 100.0 & \\
\hline
\end{tabular}

Source: Authors' compilation, 2020

Table 1b Respondents' Marital Status

\begin{tabular}{|r|l|r|r|r|r|}
\hline \multicolumn{7}{|c|}{ Marital Status } \\
\hline \multirow{3}{*}{} & Frequency & Percent & Valid Percent & $\begin{array}{c}\text { Cumulative } \\
\text { Percent }\end{array}$ \\
\hline \multirow{4}{*}{ Valid } & Single & 42 & 22.0 & 22.0 & 22.0 \\
\cline { 2 - 6 } & Married & 145 & 75.9 & 75.9 & 97.9 \\
\cline { 2 - 6 } & Divorsed & 4 & 2.1 & 2.1 & 100.0 \\
\cline { 2 - 6 } & Total & 191 & 100.0 & 100.0 & \\
\hline
\end{tabular}

Source: Authors' compilation, 2020

\section{Table 1c: Respondents' education}

\begin{tabular}{|c|c|c|c|c|c|}
\hline \multicolumn{6}{|c|}{ RespdtEdu } \\
\hline \multicolumn{2}{|c|}{ Level of Education } & Frequency & Percent & Valid Percent & $\begin{array}{l}\text { Cumulative } \\
\text { Percent }\end{array}$ \\
\hline \multirow{7}{*}{ Valid } & O'Level & 19 & 9.9 & 9.9 & 9.9 \\
\hline & NCE/OND & 46 & 24.1 & 24.1 & 34.0 \\
\hline & HND/B.Sc & 88 & 46.1 & 46.1 & 80.1 \\
\hline & MBA/M.Sc & 31 & 16.2 & 16.2 & 96.3 \\
\hline & PhD & 4 & 2.1 & 2.1 & 98.4 \\
\hline & \begin{tabular}{|l} 
Others \\
\end{tabular} & 3 & 1.6 & 1.6 & 100.0 \\
\hline & Total & 191 & 100.0 & 100.0 & \\
\hline
\end{tabular}

Source: Authors' compilation, 2020

Table 1d: Firm's Age

\begin{tabular}{|l|l|r|r|r|r|}
\hline \multicolumn{2}{|c|}{ FirmAge } \\
\hline \multirow{4}{*}{ Firm's Age } & Frequency & Percent & Valid Percent & \multicolumn{2}{c|}{$\begin{array}{c}\text { Cumulative } \\
\text { Percent }\end{array}$} \\
\hline \multirow{4}{*}{ Valid } & FirmAge $<5$ & 95 & 49.7 & 49.7 & 49.7 \\
\cline { 2 - 6 } & FirmAgebtw 6 and 10 & 66 & 34.6 & 34.6 & 84.3 \\
\cline { 2 - 6 } & FirmAgebtw 11 and 15 & 17 & 8.9 & 8.9 & 93.2 \\
\cline { 2 - 6 } & FirmAge $>16$ & 13 & 6.8 & 6.8 & 100.0 \\
\cline { 2 - 6 } & Total & 191 & 100.0 & 100.0 & \\
\hline
\end{tabular}

Source: Authors' compilation, 2020 